\title{
Seven pillars and five minds: small business workplace information literacy.
}

LOCKERBIE, H., WILLIAMS, D.

2019 


\section{Emerald Journal of $\begin{gathered}\text { Documentation } \\ \text { D }\end{gathered}$}

\section{Seven Pillars and Five Minds: Small Business Workplace Information Literacy}

\begin{tabular}{|r|l|}
\hline Journal: & Journal of Documentation \\
\hline Manuscript ID & JD-09-2018-0151.R1 \\
\hline Manuscript Type: & Article \\
\hline Keywords: & $\begin{array}{l}\text { Information literacy, Small to medium-sized enterprises, Theory, } \\
\text { Competences, Workplace, Information research }\end{array}$ \\
\hline \multicolumn{2}{l}{} \\
\hline
\end{tabular}




\title{
Seven Pillars and Five Minds: Small Business Workplace Information Literacy
}

\begin{abstract}
Purpose: To develop and test a theoretical framework for understanding information literacy (IL) within the context of a small business workplace environment. The theoretical framework developed related IL competencies to competencies for success as described by the psychologist Howard Gardner in his book "Five Minds for the Future".

Design: A theoretical framework was developed using the CILIP Seven Pillars for Information Literacy and Howard Gardner's Five Minds theory. Indicative connections between the Seven Pillars and Five Minds were identified by the researchers. The framework was tested through analysis of transcripts from qualitative interviews conducted with four small business owners. Findings: Connections were found between the Seven Pillars and the Five Minds; somewhich had been projected by the researchers and others which had not. The theoretical framework aided description of and understanding of IL within small business workplace environments. Research limitations/implications: A small sample size limits the generalisability of the findings, and further testing of the framework is required. The findings do, however, suggest that the context in which IL manifests remains significant and should be further examined in wider and divergent contexts.
\end{abstract}

Originality/value: Using theory from psychology paired with a well-known theory of IL to develop a new theoretical framework is novel. The framework developed offers a new way of understanding the role of IL within the context of small business workplaces.

\section{Keywords}

Information Literacy; small businesses; theoretical framework.

\section{Introduction}

Defined as "the ability to think critically and make balanced judgements about any information we find and use" (CILIP 2018), information literacy (IL) is arguably the most valuable life skill required as the world - government services, education provision, socialisation, economic advancement - becomes increasingly information, knowledgeand technology reliant and intensive. IL has been linked to both lifelong learning and participation in the Information Society (Prague Declaration, 2003). A concept which began in libraryand education contexts, IL has increasingly become a focus of research in workplace environments. This paper describes the development and testing of a theoretical framework for conceptualising IL in small business workplace environments, using a well-known model of IL and theory from psychology, in a small scale "proof of concept" study.

\section{Literature Review}

Numerous descriptions, frameworks, skill sets and concepts of IL exist (c.f. ACRL, 2015;ANZIL, 2004; CILIP, 2018). These have historically been developed in and focussed on educational and information service contexts (see for example: Bruce, 1995; Webber and Johnston, 2003; Rader, 2002), and much IL research has been conducted in educational settings (seefor example: Doyle, 1992; Bruce, 1995; Johnston and Webber, 2003) with focus on students of business (see for example: Feast, 2003; Varga-Atkins and Ashcroft, 2004; Sokoloff, 2012) and engineering and technology (Tucker and Palmer, 2004). Such studies, however, remain inwardly focused measuring students' information skills (Varga-Atkins and Ashcroft, 2004; Walsh, 2009), and effective ways of implementing IL instruction (Feast, 2003), rather than exploring more deeply the skills required for entry into an increasingly information heavy 
working environment. There have been attempts to acknowledge the need for IL skills beyond traditional environments and the emergence of concepts such as 'digital literacy' (see for example Bawden, 2008) and ' $21^{\text {st }}$ century literacy' (The New Media Consortium, 2005) seek to address this. Recent revisions to IL descriptions and frameworks (ACRL, 2015; CILIP, 2018; SCONUL, 2015) clearly represent a shift change in understanding that IL manifests in differing contexts dependent on the environment, with workplaces taking a more prominent role in IL descriptions.

Achieving an understanding of IL in the workplace is challenging as a 'tick the box' approach to IL instruction and measurement, described by Webber and Johnston (2000), does not allow for effective observation of IL outwith structured, educational contexts. In reality IL is not a linear, unit driven process; it is messy, ever changing and difficult to understand (Mutch, 2000), made ever more difficult in workplace contexts where goals shift and the 'proper' way of doing things may not actually be conducive to working quickly, cheaply or for addressing business goals and drivers. There have been explorations of IL in workplace settings; Hepworth and Smith (2008) studied the IL of non-academic staff in higher education which uncovered a more fragmented realisation of IL in the workplace than in academic contexts; Lloyd (2004) explored the information practices of fire fighters and concluded that conceptions of IL from an educational context do not adequately describe IL in workplace settings; Katz et al (2010) assessed the relationship between IL and writing for business and suggested there should be greater acknowledgement of the enhancement IL can bring to business communication practice. Research has also been carried out into the role of information in business workplace environments. The role information plays in successful business mechanisms has been highlighted (Grieves, 1998) and the context in which decisions are made influences the interchange of data, information and knowledge (Cortado, 2009). Williams et al (2014) presented an annotated bibliography on the relevance of IL in the workplace which identified 41 items specifically relating to IL in the workplace. Theirsummary highlighted descriptions of workplace IL which focus less on formal searching and finding skills tending to be associated with IL education. More recently Wu (2018) has explored the relationship between IL, creativity and work performance, and Middleton et al (2018) have looked at IL and innovation in workplaces, suggesting a shift in understanding about the role IL plays in more fuzzy work goals. Ultimately to understand the transferability of IL the way IL manifests in different environments needs to be understood. (Webber and Johnston, 2017). Forster (2017) brings together a range of recent research into IL in the workplace, examining IL from an experiential perspective and emphasising that IL is experienced differently in different contexts. Much of this workplace IL research has focused on professional contexts and/or within larger organisational settings, and little is known about the role and value of IL within SMEs.

With 21 million small and medium enterprises (SMEs) in the EU, employing 88.8 million people (European Commission, 2015) they represent a significant proportion of both the workforce and of economic contribution. SMEs are defined by both their employee numbers and turnover or balance sheet figures, and are categorised as micro, small or medium. There have been very few studies which have explored IL and SMEs. De Saulles's (2007) exploratory research into IL amongst UK SMEs concludes that government initiatives have focused too strongly on the ICT requirements of SMEs, instead of the underlying information skills required to use such technologies effectively, an issue noted by others (see for example: De Saulles, 2008; Duan et al, 2002).

Williams (2003) found SMEs can lack the expertise to conduct effective research: with limited awareness of information sources and ability to evaluate and understand information. This could impact an SMEs competitive advantage, and therefore its ability to survive and thrive. 
High costs have been attributed to information work (see for example: Bates, 2004; Cheuk, 2002; De Saulles, 2007; Feldman and Sherman, 2001) and employee time, irrespective of company size or turnover, is a valuable commodity to business. Searching for, accessing, and synthesizing information for business needs takes time, and enhanced IL abilities can save time and money. IL exists in workforces (Kirkton and Barham, 2005) but is describedusing different terminology which makes it difficult to transfer IL theories and understanding into workplace contexts. It has been suggested that corporate terminology be applied to information concepts which are relevant to the workplace (O'Sullivan, 2002). This paper describes research which aimed to develop a new framework for understanding the role of IL within a SME environment.

\section{Research Methodology}

As part of a masters' programme the research was conducted in two stages: 1) the development of a theoretical framework which combines existing IL theory with a model of workplace competency; 2) conducting interviews with small business owners to test the theoretical framework and refine the relationships established in the framework.

\section{Stage 1- Development of a theoretical framework}

A theoretical framework was developed to assist in understanding IL in small business workplaces. A framework is defined as a structural plan, or basis of a project and the term is used in relation to IL elsewhere (e.g. NHS Scotland Information Literacy Framework, TheWelsh National Information Literacy Framework, ACRL Framework for Information Literacy for Higher Education). Requirements for the framework in this research were that it should combine a well-developed IL model with a complementary frame of analysis which would illuminate the relationship between IL and effective working and the achievement of business goals. The framework should enable examination of the realities of IL for an individual who may never have had exposure to the concept of IL or received any formal instruction or skill development in IL. The models chosen were SCONUL's Seven Pillars of Information Literacy (2011), offering a current (at time of research) process and competency driven model of IL, and Howard Gardner's Five Minds for the Future (2008) which focuses on outcomes. Thus the first stage of the research was achieved by mapping current IL terminology of the Seven Pillars against the Five Minds descriptions of abilities and requirements for success in the workplace, developing a layered frame of analysis for understanding IL in small business workplaces.

\section{Stage 2 - Testing the theoretical framework}

Testing was carried out by conducting in-depth interviews with four SMEs. An invitation to participate in the research was sent to SMEs within a 50 mile radius of the researchers workplace to allow for face to face interviews where possible. The SMEs invited for interview were identified through OneSource, a business information database. A search was conducted for micro, small and medium sized enterprises in the designated area. In total 70 SMEs were invited to participate in the research, and four responded; three micro sized and one medium sized company. The number of participants achieved for the research was not surprising as SMEs are small companies with limited resources, especially time. Although a small sample size the participants interviewed were willing to give their time to engage in in-depth interviews which provided rich and illuminative data.

Interview questions were developed through critical review of literature to allow participants to describe how they effectively use information and demonstrate their awareness of the value of information. This approach facilitated elicitation of experiential IL through deep, qualitative responses. Questions were assimilated into themes: general questions; finding information; information needs for working in a business context; information forbusiness 
success; information management and people; and end questions. A pilot interviewwas conducted with a SME owner known to the researcher. The four research interviews lasted between 20 and 45 minutes; two were conducted via telephone, one via Skype and one face to face. All interviews were recorded with verbal permission from the participant. The theoretical framework was then tested using relevant verbatim transcripts of interviews, which were analysed and coded twice - once using the Seven Pillars and again using the Five Minds. First each interview was analysed looking for instances of the Seven Pillars and the associated competencies, which were assigned a code and marked up on each transcript. This was repeated, looking for instances of the Five Minds which were assigned a code and areas of the interview where these appeared were marked up. The researcher cyclically read through descriptions of the Seven Pillars and Five Minds when coding the interviews to ensure definitions were understood. When a pillar or mind was thought to be represented in an interview, the specific definition would be read alongside the interview transcript. This process resulted in two annotated transcripts for each interview, which were then considered side by side to identify areas of the interview in which there was overlap between the seven pillars being identified and the five minds being identified, which established connections between the Seven Pillars and Five Minds. These connections were used to refine the theoretical framework.

\section{Findings}

\section{Stage 1 - Developing a Theoretical Framework}

The current SCONUL Seven Pillars of Information Literacy were published in 2011 and reflect the range of terminologies and concepts which have become associated with and used to describe IL. An increase in such range has led to the development of a 'core' model for IL in Higher Education and various 'lenses' though which different groups of learners can be viewed (SCONUL, 2011). Currently there exists a lens for research, digital literacy, open educational resources, evidence-based practice healthcare and graduate employability (Goldstein, 2015). For the purpose of the present study the 'core' model was selected as it is the most generic and therefore theoretically transferable into different environments.

This 'core' model defines the skills and competencies (abilities) and attitudes and behaviours (understanding) which are central to IL development in higher education, also considered essential for lifelong learning. The model recognises the information context, or the 'world of information as perceived by an individual at that point in time' (SCONUL, 2011 p.4).

The Seven Pillars model defines what should be understood for each pillar (identify; scope; plan; gather; evaluate; manage; present) and how this understanding is demonstrated through abilities. As IL development is not a linear process, the diagrams representing the model have been designed in a circular manner. Individuals are able to develop competencies within 'pillars' simultaneously and independently, and all seven pillars are closely linked (SCONUL, 2011). As an individual demonstrates greater attributes associated with each pillar, they move up the pillars from 'novice' to 'expert' as they become more information literate.

As a psychologist Howard Gardner's work has focused largely on cognitive functions and in his monograph, Five Minds for the Future (2008), he sets out the 'minds' which must be mastered to succeed in an ever changing world. The Five Minds consist of the disciplined mind, the synthesizing mind, the creating mind, the respectful mind and the ethical mind.

Like SCONUL, Gardner places his Five Minds in educational contexts, and acknowledges that when people think of cultivating his Five Minds, the most common setting is formal 
education. However he goes on to say that "...education must be lifelong. Those at the workplace are charged with selecting individuals who appear to possess the right kinds of knowledge, skills and minds - in my terms they should be searching for individuals whopossess disciplined, synthesizing, creating, respectful and ethical minds. But, equally, managers and leaders, directors and deans and presidents, must continue perennially to develop all five kinds of minds in themselves and - equally - in those for whom they bear responsibility." (Gardner, 2008 p. 9).

The disciplined mind utilises a way of thinking associated with scholarly disciplines and professions. Someone with a disciplined mind is "capable of applying oneselfdiligently, improving steadily, and continuing beyond formal education." (Gardner, 2008 p. 154). Information is seen by Gardner as a means to better informed practice, not an end in itselfor a stepping stone to more advanced information. Gardner also recognises that information will be acquired whilst nurturing a disciplined mind, and that a "cultural literacy" will be developed (Gardner, 2008 p. 38). This 'cultural literacy' will be entrenched and flexible as it has been acquired in a meaningful context, and not forced by memory or rote learning. A disciplined mind is therefore self-perpetuating; learning deeply about something will drive the desire to learn about other things deeply too, and therefore gain true understanding.

The synthesizing mind is a mind which has the ability to select relevant information, and to present and communicate that information in ways which make sense to oneself and others, with Gardner suggesting that the "ability to knit together information from disparate sources into a coherent whole is vital today." (Gardner, 2008 p. 46). The ability to synthesize information is an integral part of being information literate and Gardner highlights the importance of synthesis in the workplace. A synthesizing mind is therefore essential for understanding the environment in which one is working.

The creating mind goes beyond existing knowledge and synthesis to pose new questions and offer new solutions; these new questions and solutions must be judged for quality and acceptability from the appropriate informed field. Having a creating mind could be described as 'thinking outside the box'. Gardner suggests that those "corporations that do notembrace innovation will almost inevitably be muscled out by those that do." (Gardner, 2008 p. 78). A creating mind is therefore essential for business success. Like the Seven Pillars, crossovers can be seen between the minds (as with the pillars) as no mind (or pillar) exists as a silo.

A respectful mind will respond sympathetically and constructively to differences among individuals and groups, and will seek to understand and work with those who are different. The value of having a respectful mind in the workplace is that "organizations and communities work more effectively when the individuals within them seek to understand one another (despite their difference), to help one another, and to work together for common goals." (Gardner,2008 p.116-117).

Finally Gardner presents the ethical mind. The ethical mind is essentially about doing good work and being a good citizen. Gardner suggests that "if education is preparation for life, it is in many ways the preparation for a life of work. Educators should prepare young persons for a life marked by good work; the workplace and the broader society should support and sustain such good work." (Gardner, 2008 p. 128). Acting in an ethical manner is important as a leader or manager as "employees listen to what their leaders say, and, even more carefully, theywatch what their leaders do" (Gardner, 2008 p. 147). 


\section{Rationale for Using the Seven Pillars and Five Minds as part of a theoretical} framework

SCONULs Seven Pillars are a well-established model of IL and have been previously used in studies on IL conceptualisation (see for example: Corral, 2008; Boon et al, 2007; Martin, 2013). Such studies have demonstrated the wide acceptance and adoption of SCONULs Seven Pillars, as an authoritative, generic, adaptable description of the processes associated with IL and provide justification for its use as part of a theoretical framework for understanding IL. This process driven model designed for Higher Education contexts only brings us part of the way to developing a framework to allow for the understanding of IL in workplace contexts. Whilst the process of IL is important in the workplace process can be overridden by business goals. An understanding of the outcomes of IL in relation to business goals and values is necessary to truly be able to investigate and understand IL in workplace settings - this provides the basis for the inclusion of Howard Gardner's Five Minds for the Future as part of a theoretical framework.

Gardner's Five Minds have been used to illustrate the skills required for 21st centuryliving. Kay and Greenhill (2011) pay particular attention to the disciplined mind in aneducational context. The authors suggest that a common debate in education of 'content vs. skills' can be calmed by developing a deep mastery in core subjects (like Gardner's disciplined mind suggests), mastered with an emphasis on skills. The use of Gardner's minds to facilitate discussions of 21st century skills suggests that the Five Minds could be a good way to take IL research forward, especially as Kay and Greenhill (2011 p. 52) go on to say "this is the nature of our society and our workplaces today - less emphasis on silos of knowledge, and more reliance on 21st century skills."

In the LIS domain, Webber and Johnston (2017) have highlighted that IL research has been complemented by insights from subjects such as psychology. Bawden (2008) has highlighted the importance of synthesis. He picks out Gardner's Five Minds, especially thesynthesizing mind as being "identified as a breakthrough idea in 2006 by the Harvard Business Review." (Bawden, 2008 p. 29). More recently Bawden and Robinson (2011) tackled differences in individual information related behaviour and in doing so identified Gardner's Five Minds suggesting that "given the close links between these 'five minds' and the handling of information and knowledge, this categorization seems appropriate as a basis forinformation style typology. It does not, however, seem to have been applied, as yet, within the information sciences." (Bawden and Robinson, 2011 p. 149). Their recognition of the applicability of the Five Minds to information related concepts further fuels the rationale for using the Five Minds as part of the theoretical framework.

Howard (2012) considers Gardner's Five Minds as a component of a 'thinking organisation' and proposes an underlying model for manager's thinking, applicable to both individuals and organisations. The use of Gardner's Five Minds in both academic and practical situations again proves the value of using the Five Minds in the current study, especially when exploring the relationship between IL (an academic conception) and business outcomes (practical situations).

Gardner describes his work as "ambitious, even grandiose" (2008 p. 153). However, such ambitious work is required to effectively conceptualise and understand the skills required for success in the complex world we live in today. In the workplace this complexity is magnified by the sheer amount of information individuals must deal with in order to be disciplined, synthesizing, creative, respectful and ethical. IL can therefore be seen as a stepping stone to achieving Gardner's Five Minds, as without IL one would not be able to engage with the 
information world which would allow these minds to be developed. IL is essential for being an effective worker and a lifelong learner; Gardner also argues that the Five Minds are essential for success and lifelong learning. The Five Minds could therefore be a product of being information literate. Whilst the process of IL is an important consideration, it is also important to recognise the product of being information literate and how this manifests in a workplace setting. The Five Minds are part of this manifestation. Using Five Minds as a way to enhance observation of the process of IL will aid in understanding how IL manifests in the workplace. Bringing together the Seven Pillars and Five Minds gives a contextualised approach to understanding IL which combines the process and outcomes, enhances understanding, descriptions of, and manifestations of IL in the workplace.

Whilst exploring and understanding the Seven Pillars and Five Minds, indicative connections between the Seven Pillars and Five Minds were identified, illustrated in Table 1. The shaded areas indicate where connections are theorised to exist between the Seven Pillars and Five Minds. These potential links are based on instances where the Seven Pillars were immediately identifiable in the descriptions of the Five Minds. For example, the disciplined mind, which includes the acquisition of information, was felt by researchers to be represent aspects from the identify pillar which describes individuals having an understanding of the need to actively seek information and the scope pillar which describes the ability to identify information/knowledge gaps and utilise skills to fill that gap. The synthesizing mind includes the ability to select, present and communicate information, which encapsulates the description of both the scope pillar (as above) and the present pillar which includes a description of being able to synthesise new and old information. As the creating mind is described as being able to present new solutions which are developed with quality information, the plan pillar was expected to be linked with the creating minds through the ability for individuals to construct strategies for locating information and data. The respectful mind would reflect the evaluate pillar as having the ability to appreciate differences amongst groups was thought to translate well into the judging of information sources, bias, reputation and credibility. Finally researchers identified the ethical mind to highlight the evaluate pillar as described above, but also the manage pillar which is about the ability to organise information professionally and ethically.

\section{Table 1: Indicative theoretical links between Seven Pillars and Five Minds}

\section{A Note on Frameworks and Theories}

A theoretical framework is defined as a representation of "beliefs on how certain phenomena (or variables or concepts) are related to each other (a model) and an explanation of why you believe that these variables are associated with each other (a theory)" (Sekaran and Bougie, 2009 p. 69).

Robson and Robinson (2013) discuss the term 'theoretical framework' in theinformation behaviour domain. Recognising there is little consensus of the meaning and the value of the term between scholars, they suggest "it is legitimate to ask what their value is and how far they build on each other to develop understanding of information behaviour in a practically relevant way" (p. 170). Jarvelin and Wilson (2003) suggest that conceptual models should be used rather than theoretical models. It would appear that, similarly to IL itself, there are issues surrounding the terminology used to describe frameworks. Davies and Williams (2013) developed a conceptual framework as a way of linking literature and research questions, and to inform research design. The resulting framework allowed for information providers to map individual and organisational information behaviour and aided in supporting understanding of internal information environments. 
In the present paper the term theoretical framework has been adopted to represent the building upon existing models and theories. The authors do not believe the term conceptual model appropriately reflects the composition of the framework; it is not a composition of concepts, but is rather a composition of theoretical lenses through which IL can be viewed in a workplace context. Like other theoretical frameworks, its value will be demonstrated through testing with empirical research. Regardless of the terminology used to describe the framework presented in this paper or other similar attempts at building new ways of viewing information related concepts, the underlying purpose remains paramount: the need to build upon and advance our field and to interrogate our current conceptions, drawing on influences from a wide range of fields.

\section{Stage 2 - Preliminary Testing and Refinement of the Theoretical Framework} Interview transcripts were analysed using the theoretical framework as described in the methodology section above. Demonstration by interviewees of the Seven Pillars is summarised in Table 2 and demonstration of the Five Minds is summarised in Table 3.

\section{Table 2 - Summary of Seven Pillars demonstrated by interviewees.}

\section{Table 3 - Summary of Five Minds demonstrated by interviewees.}

Examples of how the Seven Pillars and Five Minds manifested in interviews are given and discussed below.

\section{Examples of the Seven Pillars as demonstrated by interviewees}

\section{Identify}

The pillar 'identify' is the ability to identify a personal need for information. When explaining the scope of their company and what they considered to be information, interviewee one demonstrated their ability to identify a lack of knowledge in a subjectarea:

"the sort of questions I get asked are in relation to my specialist expertise which is drilling holes in the ground. Now there are certain things which I know I don't know anything about because I know I'm not sufficiently expert in these things, if people ask me for these kinds of questions I don't even bother going to look for the information, I just tell them I don't know. But if theseare things where I do know or my knowledge is incomplete then I will usually go to the SPE One Petro library and maybe occasionally using Google I will go and search some of the trade publications or magazines." (Interview One)

Abilities associated with the identify pillar are being used here to make decisions regarding what work will be undertaken and how information can be used to drive a business goal forward (i.e. answering someone's question).

\section{Scope}

The second pillar 'scope' is being able to assess current knowledge and identifygaps. Interviewee two spoke of their ability to know what they didn't know:

"...one of our secretaries in the office every morning she actually goes through all thenews media and she pulls together any news media stories that are applicable to Nigeria, applicable to us, or applicable to our competitors... we find that vital...most oil companies do have someone who does that for them. Sometimes it's $a$, in the UK in particular there is a 3rd party service that you can subscribe to, but there isn't one in Nigeria, so we do that ourselves." (Interview Two) 
The interviewee not only acknowledges a general information gap in Nigeria, but identifies that this is a gap which needs to be filled for the success of their business and takes appropriate steps to fill it. The interviewee's knowledge of the variety of information sources which are required for business information was demonstrated when asked if the company subscribed to any information services, which they did. The ability to identify which types of information will best meet their need was further demonstrated by theinterviewee's knowledge of types of information sources they must subscribe to in order to continuetheir business.

\section{Plan}

The 'plan' pillar is the ability to construct strategies for locating information and data, and was the pillar least present in the research interviews, only evidenced in interview one and two. Interviewee one demonstrated their ability to select the most appropriate search tools in their knowledge of the One Petro database:

"...OnePetro technical literature database which is exceedingly powerful and basically has all the reputable technical papers in my specialism that's been published in the last 50 years" (Interview One)

Interviewee one also demonstrated their ability to identify appropriate search techniques to use as necessary when using the OnePetro database:

"It's a very simple search you either use the new search as I was doing just put in a few keywords and see what comes back or you can do as I was doing last night and use the special search and put in the authors names and pull up all his papers" (Interview One)

Whilst not explicitly demonstrating an overall awareness of the information landscape and all of the tools which could be used, the interviewee demonstrates awareness of the tools most appropriate for their business needs, and of the search strategies most appropriate to both the tool and the need. Interviewee two displayed their ability to identify specialist tools appropriate to individual information needs by subscribing to a specialist information services:

"we do subscribe widely to third party data who collate information sometimes on a confidential basis" (Interview Two)

Again whilst this does not demonstrate a high level of searching competency, it does demonstrate an awareness of the need for information from different sources.

\section{Gather}

The 'gather' pillar is about locating and accessing information and data. Interviewees were asked if they kept up to date with industry news, how they did this and which sources of information they trusted most for this kind of information. Interviewee four demonstrated their ability to gather information from different sources and keep up to date with new information:

"Reading industry magazines, articles, little bit of Linkedln but not too much... Certainly it would be the industry magazines, you know like KTP and some of the World Oil's and things, and going 
They also demonstrated their ability to identify when the information need has not been met and the ability to identify new ways of gathering information:

"...well normally you'd go into the second one, which is doing your due diligence youknow, contacting the company directly and finding out what their situation is and how they go about business." (Interview Four)

Although this is at a basic level (not being able to find information via the internet, sopicking up the telephone to directly speak to a company) it represents an awareness of the different options for gathering information, and a willingness to use those sources.

\section{Evaluate}

The 'evaluate' pillar is about being able to review the research process, comparing and evaluating information and data. Interviewee one demonstrated their ability to 'evaluate' and assess the quality, accuracy, relevance, bias, reputation and credibility of the information sources found and to assess the credibility of data gathered. When asked what factors they considered when identifying information for business use, they responded:

"credibility and reputation of the source... basically, you know if it's going to be written by a journalist in an oil industry magazine it's probably going to be diluted and you're therefore either going to have to read between the lines or join the dots... whereas depending again on who the author is there is ascending scale of quality and reliability to the information" (Interview One)

Having knowledge of information sources and the reliability of the information which they provide can be critical when identifying information for business use.

\section{Manage}

The 'manage' pillar is about being able to organise information professionally and ethically. Interviewee one commented on the inclusion of ethics in the definition of an information literate person stemmed from, and went on to say:

"I would say the whole thing about ethics is an interesting one because it's one of those things that, there actually isn't a training course in information ethics, meaning all the things you said about copyright is actually not well explained, ... then you know certainly when I'm writing papers I have a lot of conversations with various people I get drafts, you know I stick all their names on the acknowledgements but you know this sort of etiquette of information, if you say there's one gap in it, the etiquette is not explicit... fair enough OnePetro when you download it says this article is for individual use only and some magazines when you print they very definitely have, you know, copyright not for further publication, but when you go to Google images it's not specifically clear that yeah, you can look at the images, but if you're writing a technical paper unless you've got the authors permission you can't just cut and paste it into a paper." (Interview One)

Here we see clear evidence of the pillar 'manage' and the demonstration of awareness of issues relating to the rights of others including ethics, data protection, copyright, and plagiarism. This was the only example from the research interviews of an awareness of the rights issues associated with the use of information.

The three other interviewees all demonstrated some level of using data management techniques to manage their data: 
"Well we store it to start with, so we store it and make it accessible for the future" (Interview Two)

"I'm trying to store as much electronically as I can, even to the extent of my company buying a document scanner... all my PDFs are OCR'd [Optical Character Recognised] so the photograph becomes text as much as possible." (Interview Three)

"It's all digital, we don't store files at all...I've got loads of folders which I transfer theinformation into. Then I do irregular backups." (Interview Four)

There was not a great level of awareness of data management techniques in the SMEs interviewed, although there was evidence of some system being implemented.

\section{Present}

The 'present' pillar is about being able to apply knowledge gained. Interviewee three demonstrated their ability to synthesize and appraise new and complex information from different sources when talking about the use of new software:

"software is wonderful but at the end of day ... knowledge and keeping on top of your customers and competition is much better than having something, which you know, you put in the numbers and all this comes out ... electronic data type stuff." (Interview Three)

Whilst showing a reluctance to embrace software to enhance business operations, the interviewee does so for what they feel are good business reasons. Being able to evaluate information from different sources yourself is better for business:

"...people buy from people despite how big and how people try to disembody some of theirwork on that by putting it through various systems, it is a people thing." (Interview Three)

\section{Evidence of the Five Minds as demonstrated by interviewees}

\section{Disciplined Mind}

The disciplined mind is the mastery of traditional academic subjects and professional crafts. There was evidence of the disciplined mind in each interview conducted. Interviewee two demonstrated having a disciplined mind when asked if there was a certain strategy followed when seeking new information:

"Well I want it from credible sources, and because there's nothing worse than taking information from a source that you subsequently find out is not credible, and that's damaged your own credibility, because you've then repeated that information to others, only to find out that it's either an error or it's just not true at all." (Interview Two)

This is evidence of the disciplined mind, as the interviewee would not be able to know if information was credible without having some disciplinary knowledge of their businessarea. There is also a certain amount of diligence evident, as well as the ability to identify reliable information sources. Traits of the disciplined mind are essential for establishing the credibility and value of information to the business. 


\section{Synthesizing Mind}

The synthesizing mind is the ability to integrate information from many sources, Explicit manifestation of the synthesizing mind was visible when interviewee one was asked how they know if information has had a positive or negative effect on their business, suggesting this was through client satisfaction and being able to write a good report:

"... it's a combination of one's experience and ones knowledge of a discipline and whatother information you've been able to pull in to your recommendations" (Interview One)

We can actually see the disciplined mind and the synthesizing mind working together; the interviewee states they use knowledge of their discipline and combine this with other information, which is then synthesized to accomplish a business goal.

\section{Creating Mind}

The creating mind is the ability to uncover and clarify new ideas. Interviewee three demonstrated a creative mind:

"[I'm] currently looking into recovery pipelines... most of my work has been project orientated, so one off challenges. So I had to go out and look for a big set of scissors to cut the pipe up...things to grab it and put it in baskets and things like that in the market." (Interview Three)

Here we see an example of the creating mind, in the interviewees' ability to come up with new solutions to problems for clients, and suggests that most of their career has been spent facing business 'challenges'. A creating mind could be argued as essential for a career in which problem solving plays a critical role.

\section{Respectful Mind}

The respectful mind is about appreciating different cultural perspectives and working with others who are different in an effective way. Interviewee one demonstrated a respectful mind when talking about their network:

"oh and the final source of information is my very large network of professional colleagues... I was on the phone to a guy in Dubai who had problems in the East African lakes - about which I've been asked a question - I phoned him [as] I knew he was working there...so basically information comes not just from the published literature but from having a good network and following up your network contacts" (Interview One)

There is evidence of the respectful mind in the interviewee's ability to understand differences between individuals, their experience and what value can be brought by working together. This results in a more effective way of working, with the ability to tap into a network rich with information which may otherwise take a long time to uncover.

\section{Ethical Mind}

An ethical mind enables responsible behaviour. The ethical mind was demonstrated in comments from interviewee one regarding ethics and information use:

"I would say the whole thing about ethics is an interesting one because it's one of those things that, there actually isn't a training course in information ethics... it's a bit like good manners, if you don't have your mum to teach you good manners you never learn good manners and will behave like an animal, and unless you pick it up at university and its drummed into you that you always acknowledge your sources..." (Interview One) 
There is evidence of responsible behaviour in acknowledging those who have contributed, but also a greater awareness that these issues are not well understood in wider society. There is also evidence of the interviewee modelling their behaviour on lessons picked up at university, comparing this to lessons learned from parents. This is an interesting insight, indicating that ethical information use may come from observing others.

\section{Connections between the Seven Pillars and Five Minds}

The selection of examples provided from the interviews gives an indication of the connections between the Seven Pillars and Five Minds, demonstrating their potential value as a theoretical framework for understanding IL in workplace environments. In terms of the 'identify' pillar, the identification of information is useful to not only understand individual business goals, but also to understand the wider business environment and an individual's place within that environment. These abilities draw on the qualities associated with the disciplined mind and the synthesizing mind. Identifying information also plays a part in making decisions about what business goals should be, how the work will be undertaken, and what information is necessary and applicable to achieve those goals. There is evidence of background information being used not just to identify traditional sources of information, but also in establishing where knowledge and information may lie in a personal or professional network. There was evidence of identifying what you don't know in order to answer a question. We see connections between these abilities and the disciplined, synthesizing and respectful minds.

The 'scope' pillar and its associated abilities in the small business environment were demonstrated by interviewees. There was evidence of individuals being able to identify types of information needed for their business, as well as awareness of the various sources information can come from, underpinned by the disciplined mind. Some interviewees paid for information in order to have access to the right information for the business context. There was evidence of knowledge gaps helping to decide which business assignments would be considered. Wider information gaps in the business operating environments were also identified, with the appropriate steps taken to fill them. This is the synthesizing mind atwork.

There was little manifestation of the 'plan' pillar in the research interviews. Where the abilities associated with the plan pillar were evident they were in relation to being aware of information sources that best suit business needs and using different search techniques.

Interviewees demonstrated the ability to gather information for business needs. There was evidence of interviewees engaging with not just printed or electronic information, but also gathering information from their network and individuals. There was no evidence of creating complex searches, or of any of the interviewees engaging with expert help to do so. This could be a trait of the disciplines the interviewees come from (technical, engineering), or it could demonstrate low levels of IL in the interviewees. Or indeed the interviewees just may not have recalled any examples of this when speaking with researchers.

In the business context the key focus of the abilities associated with the evaluate pillar is assessing the accuracy and credibility of information, which can shape businesspractices. There were examples of being able to distinguish between different sources of information and there was also one example of critical reading. There was little evidence of choosing information suited to a search topic, although it could be argued this is due to lackof interviewee articulation rather than this not happening. There was little evidence of search topics being explicitly identified, and rather a grazing or 'I know where to find that information' approach is taken. This could be underpinned by disciplinary knowledge orone's network. We see here the synthesizing mind in the presentation of findings and in the 
completion of business assignments. We also see the respectful mind in engagement with networks.

There was little evidence of the abilities associated with the manage pillar, but this could have been due to the interviews being conducted primarily with micro sized companies, where there is only one employee. The impression interviewees gave was that there was not much need to have any information management systems in place (it could be argued this is because they have not understood the benefit this would bring). The presentation of information found (and synthesized into the business context) can be formal orinformal, written or verbal. The presentation of information is often at the end of a business task or once services have been completed. There are clear associations between this and the synthesizing mind, and the respectful mind through engagement with people.

When developing the theoretical framework, and before analysis of the interviews was conducted, indicative connections between the Five Minds and the Seven Pillars were identified (See Table 1). Table 4 represents the indicative connections pre-analysis (shaded areas) and the actual findings identified post-analysis of the interviews (marked by across).

\section{Table 4 - Findings from research interviews compared with potential relationships identified}

While many of the projected connections were exemplified within interviews somenew connections emerged. The implications of these findings are discussed below.

\section{Discussion}

Pre-analysis, potential connections were identified between the disciplined mind and the identify, scope, plan and evaluate pillars. However there was evidence in the interviews of the disciplined mind in relation to the identify, gather, evaluate and present pillars. The disciplined mind was primarily evident when identifying gaps in individual knowledge, based on disciplinary awareness. Without the fundamentals of a discipline, the ability to do so would be significantly reduced. Engaging with a discipline and displaying a desire to continue learning past formal education is a fundamental element of the disciplined mind, as it is for IL. Williams (2003) identified a lack of awareness in SMEs of information sources and suggested they demonstrated little ability in being able to evaluate and understand information; the current research found respondents displayed awareness of information sources and demonstrated their ability to evaluate and understand information in relation to their business needs. However the present study is reliant on a small sample of SMEs and so this could not be regarded as a general statement.

Some of the SMEs interviewed paid for information from reliable and credible sources, which suggests awareness of the cost of information and the benefit of paying for some information. Despite identifying time as a factor which influences when information seeking stops, there was no explicit realisation that time spent searching also costs money, suggesting a lack of awareness of the cost of information work in the SME environment, an issue raised by Cheuk (2002), De Saulles (2007) and Feldman and Sherman(2001).

The connections identified between the synthesizing mind and the seven pillars pre-analysis were confirmed in the research interviews. The synthesizing mind was very prominent in the interviews, and works with the disciplined mind. The relationship between information use and decision making was demonstrated, with a high value being placed on both formal and informal information sources as suggested by Grieves (1998). There was evidence of the synthesizing mind being used not just in relation to individual behaviour but for the company 
as a whole. This suggests there could also be connections between the Seven Pillars and company IL, not just individual IL. This is a significant finding, as Sen and Taylor (2007) suggest that corporate information competence is a major contributing factor to organisational development. Synthesis was also predominant when using information to understand the context in which the business itself sits, which Cortada (2009) identified as being critical to success.

It was anticipated there would be high instances of the creating mind in relation to the seven pillars however, from the interviews there was only demonstration of the creating mind in relation to the identify pillar. It was surprising there was such a low representation of the creating mind from the interviews, as it could be argued creativity is essential for problem solving. Solving problems was a key task for all of the interviewees, and so this lack of the creating mind could represent a problem area. If the SMEs interviewed are not being creative in their use of information, with the limited resources they have, could this impede their ability to succeed? Desouza and Awazu (2006) suggested that SMEs must use their tacit knowledge to the fullest, do more with less, and be smart and creative in their approach to knowledge management and information use. There was little evidence from the interviews of thistaking place, although the small sample size limits the generalisability of this finding.

The respectful mind was expected to be associated with the identify, gather, evaluate, manage and present pillars. The interviews confirmed most of these connections apart from the scope pillar and the manage pillar. It is impossible to know the demographics and cultural

differences within an individual's network, but the global nature of business today and the interviewee's willingness to engage with their personal network as a source of information suggests the respectful mind would have a significant part to play.

The ethical mind was projected to be evident in the evaluate, manage and present pillars, confirmed in the interviews. However there was also evidence of the ethical mind being present when the identify and gather pillars were present. Although there was evidence of the ethical mind, this was not significantly prominent in all interviews. The interviewees werenot explicit in expressing their knowledge of the ethical use of information, and therefore there were few manifestations of the ethical mind. This could be a potential issue for the SMEs interviewed, as a lack of understanding of the ethical use of information could lead to detrimental outcomes for the business, if information is used incorrectly. There was an awareness of personal credibility being disputed if wrong information was shared.

The use of the Seven Pillars as part of the theoretical framework was useful, as it appears they are somewhat transferable into the workplace environment. However, systematically working through the abilities and understandings associated with the seven pillars provides information about the processes individuals go through, but tells us little of the complex environment in which these abilities are being used. Bringing in Gardner's Five Minds as part of the analytical framework highlighted the richness of the small business environment, and allowed there to be insight into the reasons individuals utilise their IL abilities. The Five Minds are useful for illuminating the context in which the Seven Pillars manifest, and why the abilities associated with the pillars are required for the small business workplace environment. This allowed for a greater understanding of how personal beliefs and values can influence business practice in general, but also information practices.

Interviewees with higher instances of Seven Pillars had higher instances of the Five Minds, and interviews with fewer instances of the Seven Pillars had fewer instances of the Five Minds. Although this research is exploratory, and no generalisations can be made, this suggests there may be connections between the two which would be useful for exploring IL in business 
environments. The importance of context in IL has been highlighted by numerous authors (see for example: Cheuk, 2000; Kapitzke, 2003; Mutch, 2000; Lloyd, 2010) and therefore further testing of the theoretical framework will establish if it can aid in our examination of IL in different workplace contexts, not just small business workplace contexts.

Bringing together the Seven Pillars and Five Minds creates a theoretical frameworkwhich allows understanding of IL in context akin to the liberal art suggested by Shapiro and Hughes (1996). IL is deeper than a set of skills and is more about having a holistic view of the world which enables understanding of sources, sites of knowledge and ways of knowing which result in critical thinking (Lloyd, 2017). The Five Minds are about having an awareness of the individual's place in the information world and how to operate effectively and respectfully in it. Bringing the two theories together also helps to avoid the 'tick box' approach, which Webber and Johnston (2000) caution against. The fluidity of IL has been illuminated, with the Seven Pillars not being evident in a linear order, and abilities from one pillarmanifesting alongside others. The Five Minds are also fluid, with there being interactions between them, and elements from the minds being apparent in the same situations. This research confirms the fragmented realisation of IL in workplace settings which Hepworth and Smith (2008) identified, and further supports Mutch (2000) suggestion that IL is a messy, open ended process which requires a flexible approach.

This small scale study sought to examine potential relationships between established professional descriptions/frameworks for both IL and leadership. Such frameworks provide ways of understanding the potential role of IL within workplace environments at the macro and/or organisational level. However there is a growing body of research that points to the fact that IL is likely to be experienced differently in different workplace contexts (Forster, 2017). In particular the phenomenographic approaches adopted in a range of contexts (e.g. Bruce, 1997; Cunningham \& Williams, 2018; Forster, 2015; O'Farrell, 2010; Williams \& Wavell, 2008) offer ways to enter the world of workplace IL from a more experiential and personal perspective. Although it was not within the scope of the current small study to undertake such analysis, the responses of individual interviewees contain tantalising glimpses of the potential for such research approaches within SMEs, helping develop a rich understanding of how IL may contribute both to the individual employee as well as the organisation as a whole.

It is recognized that the Five Minds is one of many theories or frameworks which could be used to understand business contexts, and others would be worthy of further exploration. The Five Minds have been useful for this study and the framework developed would be worthy of further research to confirm and refine the connections suggested in this research. Particularly further research with SMEs would be valuable as their operating environments can be so divergent but with similar challenges. Interdisciplinary research with ILS, psychology and business studies could prove particularly fruitful. This research demonstrated the need for greater contextualisation of the Seven Pillars and IL and has made a small contribution to developing IL theory through conceptual work.

\section{Conclusions}

The aim of the research was to develop and test a theoretical framework for understanding IL in small business environments. IL in the workplace is a complex and under researched area, largely due to lack of understanding of how to best facilitate its examination. The variance in workplace context aids this complexity. A theoretical framework for understanding IL in small business workplace contexts was developed, and using data gathered through interviews, the applicability of this framework was tested. The theoretical framework was successful in aiding description of and understandings of IL in small business environments as it allowed for a richer picture of the business context to be established. The present study is limited in its 
scope due to the number of interviews were conducted. The theoretical framework should be tested not only in a wider study of SMEs, but also in other workplace settings to examine its applicability outwith a small business environment. 


\section{References}

ACRL. (2015), Information literacy competency standards for higher education, ALA, Chicago, IL. ANZIL. (2004), Australian and New Zealand information literacy framework: principles, standards and practice, $2^{\text {nd }}$ ed. ANZIL, Adelaide, AU.

Bates, M. E. (2004), Free, Fee-Based and Value-Added Information Services. The Factiva White Paper Series.

Bawden, D. (2008), "Origins and concepts of digital literacy", in Lankshear, C. and Knoble, M. (eds.), Digital literacies: concepts, policies and practices. Vol. 30, Peter Lang Incorporated, pp. 17-32.

Bawden, D. and Robinson, L. (2011), "Individual Differences in Information-Related Behaviour: What Do We Know About Information Styles?", in Spink, A. and Heinstrom, J. (eds.) New Directions in Information Behaviour, Library and Information Science, Volume 1, Emerald Group Publishing Limited, pp.127-158.

Boon, S., Johnston, B. and Webber, S. (2007), "A phenomenographic study of English faculty's conceptions of information literacy", Journal of Documentation, Vol. 63 No. 2, pp. 204-228.

Bruce, C. S. (1995), "Information literacy: a framework for higher education", Australian Library Journal, Vol. 44 No. 3, pp. 158-170.

Bruce, C. (1997) Seven Faces of Information Literacy, AUSLIB Press, Adelaide, South Australia.

Cheuk, B. (2000), "Exploring information literacy in the workplace: a process approach", in

Bruce, C. and Candy, P. (eds.), Information literacy around the world - advances in programmes and research, Wagga Wagga: Centre for Information Studies, pp.177-191.

Cheuk, B. (2002), "Information literacy in the workplace context: issues, best practices and challenges", White paper prepared for UNESCO, The US National Commission on Libraries and Information Science, and the National Forum on Information Literacy, for use at the Information Literacy Meeting of Experts, Prague, The Czech Republic.

CILIP, (2018), "CILIP Definitions of Information Literacy 2018", available at:

https://cdn.ymaws.com/www.cilip.org.uk/resource/resmgr/cilip/information professional and news/press releases/2018 03 information lit definition/cilip_definition doc final f.pdf

(accessed 20 th September 2018).

Corral, S. (2008), "Information literacy strategy development in higher education: an exploratory study", International Journal of Information Management, Vol. 28, pp. 26-37. Cortada, J. W. (2009), "Power and use of context in business management", Journal of Knowledge Management, Vol. 13, No. 3, pp. 13-27.

Cunningham, V. and Williams, D (2018) The seven voices of information literacy (IL), Journal of Information Literacy 12(2), pp.4-23.

Davies, R. and Williams, D. (2013), "Towards a conceptual framework for provider information behaviour", Journal of Documentation, Vol. 69, No. 4, pp. 545-566.

De Saulles, M. (2007), "Information literacy amongst UK SMEs: an information policy gap", ASLIB Proceedings: New Information Perspectives, Vol. 59, No. 1, pp. 68-79.

De Saulles, M. (2008), "Never too small to join the party", Information World Review, Vol 249, pp. 10-12.

Desouza, K. C. and Awazu, Y. (2006), "Knowledge management at SMEs: fivepeculiarities", Journal of Knowledge Management, Vol. 10, No. 1, pp.32-43.

Doyle, C. S. (1992), "Outcome measures for information literacy within the national educational goals of 1990", Final report to National Forum on Information Literacy. Summary of Findings.

Duan, Y. et al, (2002), "Addressing ICTs skill challenges in SMEs: insights from three country investigations", Journal of European Industrial Training, Vol. 26, No. 9, pp. 430-441.

European Commission, (2015), "User Guide to the SME Definition" Publications Office ofthe European Union, Luxembourg.

Feast, V. (2003), "Integration of information literacy skills into business courses", Reference Services Review, Vol. 31, No. 1, pp.81-95. 
Feldman, S. and Sherman, C. (2001), "The high cost of not finding information: an IDC white paper", IDC, Framingham, MA.

Forster, M. (2015) Six ways of experiencing information literacy in nursing - the findings of a phenomenographic study, Nurse Education Today, 35(1), pp.195-200.

Forster, M. (ed) (2017) Information Literacy in the workplace, Facet Publishing, London. Gardner, H. (2008), Five Minds for the Future, Harvard Business Press, Boston, MA.

Goldstein, S. (2015), "Perceptions of the SCONUL Seven Pillars of Information Literacy: a brief review"

Grieves, M. (1998), "The impact of information use on decision making: studies in five sectors introduction, summary and conclusions", Library Management, Vol. 19, No. 2, pp.78-85.

Hepworth, M. and Smith, M. (2008), "Workplace information literacy for administrative staff in higher education", Australian Library Journal, Vol. 57, No. 3, pp.212-236.

Howard, A. (2012), "The thinking organisation", Journal of Management Development, Vol.31, No. 6, pp. 620-632. Jarvelin, K. and Wilson, T. D. (2003), "On conceptual models for information seeking and retrieval research", Information Research, Vol. 9, No. 1.

Johnston, B. and Webber, S. (2003), "Information literacy in higher education: a review and case study", Studies in Higher Education, Vol. 28, No. 3, pp. 335-352.

Kapitzke, C. (2003), "Information literacy: a positivist epistemology and a politics of Outformation", Educational Theory, Vol. 53, No. 1, pp.37-53.

Katz, I. R., HARAS, C. and BLASZCZYNSKI, C. (2010), "Does business writing require information Literacy?", Business Communication Quarterly, Vol. 73, No. 2, pp.135-149.

Kay, K. and Greenhill, V. (2011), "Twenty-First Century Students Need 21st Century Skills", Bringing Schools into the 21st Century, Vol. 13, pp.41-65.

Kirton, J. and Barham, L. (2005), "Information literacy in the workplace", The Australian Library Journal, Vol. 54, No. 4, pp. 365-376.

Lloyd, A. (2004), "Working (in)formation: conceptualizing information literacy in the workplace", in Proceedings of $3^{\text {rd }}$ International Lifelong Learning Conference 2004.

Lloyd, A. (2010) Information literacy landscapes: information literacy in education, workplace and everyday contexts, Chandos, Oxford, UK.

Lloyd, A. (2017), "Information literacy and literacies of information: a mid-range theory and model", Journal of Information Literacy, Vol. 11, No. 1, pp. 91-105.

Martin, J. L. (2013), "Learning from recent British information literacy models: a report to ACRL's information literacy competency standards for higher education task force", Minnesota State University: Mankato, MN.

Middleton, L. et al, (2018), "The interaction between people, information and innovation: Information literacy to underpin innovative work behaviour in a Finnish organization", Proceedings of the Association for Information Science and Technology, Vol. 55, No. 1, pp. 367-376.

Mutch, A. (2000), "Information literacy: a critical realist perspective", in Bruce, C. and Candy, P. (eds.) Information literacy around the world - advances in programmes and research, Centre for Information Studies, Wagga Wagga, AU, pp.153-162.

O'Farrill RT (2010) "Information literacy and knowledge management at work:

Conceptions of effective information use at NHS24", Journal of Documentation, 66(5), pp.706-733.

O'Sullivan, C. (2002), "Is information literacy relevant in the real world?", Reference Services Review, Vol. 30, No. 1, pp. 7-14.

Prague Declaration, (2003), "The Prague Declaration - Towards an Information Literate Society", Prague, Czech Republic: 20-23 September 2003.

Rader, H. B. (2002), "Information Literacy 1973-2002: a selected literature review", Library Trends, Vol. 51, No. 2, pp. 242-259. 
Robson, A. and Robinson, L. (2013) "Building on models of information behaviour:linking information seeking and communication", Journal of Documentation, Vol. 69 No. 2, pp.169193,

SCONUL, (2011), The SCONUL Seven Pillars of Information Literacy: Core Model forHigher

Education.

SCONUL, (2015), A graduate employability lens for the SCONUL Seven Pillars of Information Literacy.

Sekaran, U. and Bougie, R. (2009), Research Methods for Business: A Skill-BuildingApproach, 5th Edition, John Wiley and Sons Inc., Hoboken.

Sen, B. A. and Taylor, R. (2007), "Determining the information needs of small and mediumsized enterprises: a critical success factor analysis", Information Research, Vol. 12, No. 4. Shapiro, J. J. and Hughes, S. K. (1996), "Information literacy as a liberal art?" Educom Review, Vol. 31, No. 2, pp. 31-35.

Sokoloff, J. (2012), "Information literacy in the workplace: employer expectations", Journal of Business \& Finance Librarianship, Vol. 17, No. 1, pp.1-17.

The New Media Consortium, (2005), A global imperative: the report of the $21^{\text {st }}$ century literacy summit.

Tucker, B. and Palmer, S. (2004), "Integration of information literacy training into engineering Proceedings", In: Breaking Boundaries: Integration \& Interoperability: conference, Library

Automation Inc., Croydon, Vic.

Vargra-Atkins, T. and Ashcroft, L. (2004), "Information skills of undergraduate business students - a comparison of UK and international students", Library Management, Vol. 25, No.

1/2, pp. 39-55.

Walsh, A. (2009), "Information literacy assessment: where do we start?", Journalof Librarianship and Information Science, Vol. 41, No. 1, pp.19-28.

Webber, S. and Johnston, B. (2000), "Conceptions of information literacy: new perspectives and implications", Journal of Information Science, Vol. 26, No. 6, pp. 381-397.

Webber, S. and Johnston, B. (2003), "Information literacy in the United Kingdom: a critical review", in Basili, C. (ed.) Information literacy in Europe, Italian National Research Council, Rome, pp. 258-283.

Webber, S. and Johnston, B. (2017), "Information Literacy: conceptions, context and the formation of a discipline", Journal of Information Literacy, Vol. 11, No. 1, pp.156-183. Williams, J. E. M. (2003), "Export information use in small and medium-sizedindustrial companies: an application of Diamantopoulos' and Souchon's scale", International Marketing Review, Vol. 20, No. 1, pp. 44-66.

Williams, D., Cooper, K. and Wavell, C. (2014), "Information literacy in the workplace: an annotated bibliography", available from: https://www.informall.org.uk/wpcontent/uploads/2015/11/Workplace-IL-annotated-bibliography.pdf (accessed 20th September 2018).

Williams, D and Wavell, C. (2007) Secondary school teachers' conceptions of student Information literacy, Journal of Librarianship and Information Science, 39 (4), pp.199-212. Wu, M. (2018), "Information Literacy, creativity and work performance", Information Development 


\begin{tabular}{|l|l|l|l|l|l|}
\hline $\begin{array}{l}\text { Seven Pillars } \\
\text { of Information } \\
\text { Literacy }\end{array}$ & $\begin{array}{l}\text { The } \\
\text { Disciplined } \\
\text { Mind }\end{array}$ & $\begin{array}{l}\text { The } \\
\text { Synthesizing } \\
\text { Mind }\end{array}$ & $\begin{array}{l}\text { The } \\
\text { Creating } \\
\text { Mind }\end{array}$ & $\begin{array}{l}\text { The } \\
\text { Respectful } \\
\text { Mind }\end{array}$ & $\begin{array}{l}\text { The Ethical } \\
\text { Mind }\end{array}$ \\
\hline Identify & & & & & \\
\hline Scope & & & & & \\
\hline Plan & & & & & \\
\hline Gather & & & & & \\
\hline Evaluate & & & & & \\
\hline Manage & & & & & \\
\hline Present & & & & & \\
\hline
\end{tabular}

Table 1: Indicative theoretical links between Seven Pillars and Five Minds 


\begin{tabular}{|l|l|l|l|l|l|l|l|}
\hline $\begin{array}{l}\text { Seven Pillars } \\
\text { of } \\
\text { Information } \\
\text { Literacy }\end{array}$ & Identify & Scope & Plan & Gather & Evaluate & Manage & Present \\
\hline Interviewee 1 & & & & & & & \\
\hline Interviewee 2 & & & & & & & \\
\hline Interviewee 3 & & & & & & & \\
\hline Interviewee 4 & & & & & & & \\
\hline
\end{tabular}

Table 2 - Summary of Seven Pillars demonstrated by interviewees. 
1

2

3

4

5

6

7

8

9

10

11

12

13

14

15

16

17

18

19

20

21

22

23

24

25

26

27

28

29

30

31

32

33

34

35

36

37

38

39

40

41

42

43

44

45

46

47

48

49

50

51

52

53

54

55

56

57

58

59

60

\begin{tabular}{|l|l|l|l|l|l|}
\hline $\begin{array}{l}\text { Five Minds for the } \\
\text { Future }\end{array}$ & $\begin{array}{l}\text { The Disciplined } \\
\text { Mind }\end{array}$ & $\begin{array}{l}\text { The } \\
\text { Synthesizing } \\
\text { Mind }\end{array}$ & $\begin{array}{l}\text { The } \\
\text { Creating } \\
\text { Mind }\end{array}$ & $\begin{array}{l}\text { The } \\
\text { Respectful } \\
\text { Mind }\end{array}$ & $\begin{array}{l}\text { Ethe } \\
\text { Mind } \\
\text { Mind }\end{array}$ \\
\hline Interviewee 1 & & & & & \\
\hline Interviewee 2 & & & & & \\
\hline Interviewee 3 & & & & & \\
\hline Interviewee 4 & & & & & \\
\hline
\end{tabular}

Table 3 - Summary of Five Minds demonstrated by interviewees. 


\begin{tabular}{|l|l|l|l|l|l|}
\hline $\begin{array}{l}\text { Seven Pillars of } \\
\text { Information } \\
\text { Literacy }\end{array}$ & $\begin{array}{l}\text { Connection } \\
\text { with The } \\
\text { Disciplined } \\
\text { Mind in } \\
\text { interviews? }\end{array}$ & $\begin{array}{l}\text { Connection } \\
\text { with The } \\
\text { Synthesizing } \\
\text { Mind in } \\
\text { interviews? }\end{array}$ & $\begin{array}{l}\text { Connection } \\
\text { with The } \\
\text { Creating } \\
\text { Mind in } \\
\text { interviews? }\end{array}$ & $\begin{array}{l}\text { Connection } \\
\text { with The } \\
\text { Respectful } \\
\text { Mind in } \\
\text { interviews? }\end{array}$ & $\begin{array}{l}\text { Connection } \\
\text { with The } \\
\text { Ethical Mind } \\
\text { in } \\
\text { interviews? }\end{array}$ \\
\hline Identify & $\mathrm{X}$ & $\mathrm{X}$ & $\mathrm{X}$ & $\mathrm{X}$ & $\mathrm{X}$ \\
\hline Scope & & $\mathrm{X}$ & & $\mathrm{X}$ & \\
\hline Plan & $\mathrm{X}$ & $\mathrm{X}$ & & $\mathrm{X}$ & $\mathrm{X}$ \\
\hline Gather & $\mathrm{X}$ & $\mathrm{X}$ & & $\mathrm{X}$ & $\mathrm{X}$ \\
\hline Evaluate & $\mathrm{X}$ & $\mathrm{X}$ & & & $\mathrm{X}$ \\
\hline Manage & & & & \\
\hline Present & & & & & $\mathrm{X}$ \\
\hline
\end{tabular}

Table 4 - Findings from research interviews compared with potential relationships identified 